This is the final peer-reviewed accepted manuscript of:

Sangiorgi C., Tataranni P., Simone A., Vignali V., Lantieri C., Dondi G. (2017). "A laboratory and filed evaluation of Cold Recycled Mixture for base layer entirely made with Reclaimed Asphalt Pavement". Construction and Building Materials. Vol.138, Pgs. 232-239. ISSN: 0950-0618. DOI: 10.1016/j.conbuildmat.2017.02.004.

The final published version is available online at:

https://www.sciencedirect.com/science/article/pii/S0950061817301794?via\%3Dihu $\underline{\mathrm{b}}$

(C) [2017]. This manuscript version is made available under the Creative Commons AttributionNonCommercial-NoDerivs (CC BY-NC-ND) 4.0 International License

(http://creativecommons.org/licenses/by-nc-nd/4.0/) 


\title{
A laboratory and filed evaluation of Cold Recycled Mixture for base layer entirely made with Reclaimed Asphalt Pavement

\author{
Dr. Cesare Sangiorgi
}

Assistant Professor, DICAM-Roads, Dept. of Civil, Chemical, Environmental and Materials Engineering, University of Bologna, V.le Risorgimento 2, 40136, Bologna, ITALY, email: cesare.sangiorgi4@ unibo.it

$$
\text { Dr. Piergiorgio Tataranni (Corresponding Author) }
$$

PhD Student, DICAM-Roads, Dept. of Civil, Chemical, Environmental and Materials Engineering, University of Bologna, V.le Risorgimento 2, 40136, Bologna, ITALY, email: piergiorg.tataranni2@unibo.it

\section{Dr. Andrea Simone}

Associate Professor, DICAM-Roads, Dept. of Civil, Chemical, Environmental and Materials Engineering, University of Bologna, V.le Risorgimento 2, 40136, Bologna, ITALY, email: andrea.simone@ unibo.it

$$
\text { Dr. Valeria Vignali }
$$

Assistant Professor, DICAM-Roads, Dept. of Civil, Chemical, Environmental and Materials Engineering, University of Bologna, V.le Risorgimento 2, 40136, Bologna, ITALY, email: valeria.vignali@unibo.it

\section{Dr. Claudio Lantieri}

Research Assistant, DICAM-Roads, Dept. of Civil, Chemical, Environmental and Materials Engineering, University of Bologna, V.le Risorgimento 2, 40136, Bologna, ITALY, email: claudio.lantieri2@ unibo.it

Prof. Giulio Dondi Full Professor, DICAM-Roads, Dept. of Civil, Chemical, Environmental and Materials Engineering, University of Bologna, V.le Risorgimento 2, 40136, Bologna, ITALY, email: giulio.dondi@unibo.it

\begin{abstract}
Asphalt concrete (AC) recycling is probably the most cost-effective technique for the rehabilitation of stressed road pavements and for the construction of new ones. The increased interest in this technology comes from the need of reducing the costs connected to the production processes and to the use of virgin raw materials. In fact, the benefits connected to the use of Reclaimed Asphalt Pavement (RAP) are related to the possibility of substituting the natural aggregates and the virgin binder of an AC mixture, without negatively affecting its mechanical properties. When this process is made at ambient temperature (Cold Recycled Mixes - CRM), more advantages are brought about with, above all, the reduction in energy consumption and emissions during in plant production and laying, in addition to the actual possibility of achieving durable pavement layers. A CRM totally made of RAP is proposed in this research, the main goal of which was to evaluate the different physical and mechanical characteristics derived by the large use of recycled materials. According to the final mix-design, CRM does not show significant differences in terms of physical properties, when compared to a Hot Mix Asphalt (HMA) for base layers. Moreover, even if the experimental mixture
\end{abstract}


shows lower mechanical values, these are acceptable and higher than the limits imposed by the most common Italian technical specifications for Cold Mix Asphalts containing up to $30 \%$ RAP.

\section{Introduction and scope}

In recent years, a constant decrease of costs related to the construction and maintenance of civil infrastructures has been recorded. This is due to the increasing interest of public opinion in the concept of sustainable development and to the growing political awareness of environmental issues (Gomez et al., 2013) that leads practitioners to adopt more sustainable technologies and design approaches.

In this context, the pavement construction industry still represents one of the largest consumers of natural resources and raw materials (Horvath, 2003) and its negative environmental and economic effects are enhanced by the production of quantities of wastes during the maintenance and the rehabilitation of stressed roads (Celauro et al., 2010; Dondi et al., 2014).

The limited availability of virgin aggregates, the rise in prices of materials and the additional costs related to the disposal of wastes, have promoted the use of recycling technologies for the rehabilitation and construction of asphalt pavements(Dondi et al. 2013; Sangiorgi et al., 2016; Mazzotta et al., 2015).

The recycled materials used in the road construction industry are generally classified as:

- Industrial by-products, such as steel slags, blast furnace slags,fly ashes and similar;

- $\quad$ Road by-products, mainly Reclaimed Asphalt Pavement (RAP) materials;

- Construction and Demolition by-products, such as crushed concrete, mortars, tiles, bricks and similar (Chiu et al., 2008; Dondi et al., 2014; Sangiorgi et al., 2015).

In the last ten years, an ever-increasing number of these materials has been tested in addition, partial or total substitution of constituents commonly used in paving applications.

Thus different innovative and eco-friendly materials are now available on the market and a number of second-hand materials are studied, being the step of physical and mechanical characterization necessary to assess their real benefits (Dondi et al., 2014; Sangiorgi et al., 2014; Alfonso et al. 2016).

RAP, being readily available, is by far the most known and common recycled material used within asphalt mixtures, also because it partially covers the need of virgin aggregates and new asphalt binder (Pettinari et al., 2014). In the last years, different techniques and approaches have been extensively studied and applied to incorporate increasing amounts of RAP in the production of ACs. Among them Cold Mix Asphalt (CMA) recycling is now popular due to its versatile 
properties and proven environmental advantages (Pettinari et al., 2013). From an economic and environmental point of view, the possibility to produce bituminous mixtures without the addition of heat, results in a significant reduction in energy consumption and emissions during the in plant production and laying processes (Jacobson and Hornwall, 2000; Pettinari and Simone, 2015; Dondi et al., 2014). More recent studies (Silva et al, 2012; Simone et al., 2012; Abreu et al., 2015) also assessed the possibility of incorporating up to $100 \%$ of RAP in fully recycled mixtures.

The present research starts form the idea that $100 \%$ RAP can be advantageously used in cold recycling technique for the production of bituminous mixtures for eco-friendly and durable pavements. The aim is to evaluate the positive properties conferred to the mixture by using high amount of recycled materials together with binder emulsion and cement. Starting from the laboratory mix-design a full scale trial field was constructed, in order to evaluate the development of the mechanical and physical properties of the proposed CRM when compared to a high-modulus HMA for base layers.

\section{Experimental program, test methods and materials}

The experimental program was divided in two different and consecutive phases. The first one is a laboratory study in which the mix designs and the physical and mechanical properties of the two different mixtures were defined. One, labelled CRM, made out of $100 \%$ RAP material, the second one, labelled HMA, was a high-modulus asphalt concrete mixture for base layer.

In the second phase, the mixtures were laid in a full-scale test section open to heavy quarry traffic. In situ tests and samples collection were planned at regular intervals, for the evaluation of the development of the mechanical characteristics of each mixture under.

\subsection{Laboratory phase}

Nine specimens were prepared for each of the mixture with gyratory compaction (ASTM D6925). Each specimen had a dry mass of $4500 \mathrm{~g}$ and a diameter of $150 \mathrm{~mm}$, made with a constant compaction pressure of $600 \mathrm{kPa}$, external angle of $1.25^{\circ}$ and 180 revolutions.

Laboratory curing of CRM specimens has been carried out in a single way. After the production, specimens were placed in oven for 3 days at $40{ }^{\circ} \mathrm{C}$. In order to attain a full curing condition, the specimens were then kept at $20{ }^{\circ} \mathrm{C}$ until maintained a constant mass. Tests were always carried out on fully cured specimens. 
In this first step of the experimental program, the workability and volumetric properties of the mixtures were assessed by means of the compaction curves obtained at the end of the gyratory compaction. The volumetric characterization was then supported by the analysis of the air voids content of each specimen (EN 12697-8).

The static mechanical characterization included the Indirect Tensile Strength (ITS) both in dry (at $25{ }^{\circ} \mathrm{C}$ ) and wet conditions (EN 12697-12). According to the EN 12693-23 standard, the specimen was loaded by a constant velocity of $50 \mathrm{~mm} / \mathrm{min}$ until failure.

The consecutive dynamic mechanical characterization was based on the determination of the Stiffness Modulus applying indirect power to cylindrical specimens (EN 12697-26). The stiffness modulus was determined through a pulse loading with a $124 \mathrm{~ms}$ rise-time, to generate a horizontal deformation of $7 \pm 2 \mu \mathrm{m}$ in the core of the sample. Before testing, all the specimens were first conditioned for six hours at three reference temperatures: 5,20 and $40{ }^{\circ} \mathrm{C}$.

\subsection{Trial field phase}

Once defined the mix design and the physical and mechanical properties of the two different mixtures, these were laid to devise a full-scale trial field. In situ test and samples collection were planned in four dates, corresponding to 0,60 , 180 and 365 days of cumulative heavy traffic. A specific quantity of material was taken from the paving screed during the laying process and three samples for each mixture were prepared with gyratory compaction (ASTM D6925). Each specimen had a dry mass of $4500 \mathrm{~g}$ and a diameter of $150 \mathrm{~mm}$, made with a constant compaction pressure of $600 \mathrm{kPa}$, external angle of $1.25^{\circ}$ and 180 revolutions. The workability and volumetric characteristics of the mixtures were analysed by means of the compaction curves and the determination of the air voids content of each specimen (EN 12697-8). The volumetric analysis was also supported by the ITS test (EN 12697-23) at $25{ }^{\circ} \mathrm{C}$. The evolution of the mechanical characteristic of the two different mixtures for base layer was evaluated by means of the ITSM test (EN 12697-26) at $20^{\circ} \mathrm{C}$ carried out on cores. The physical properties of the two mixes were also analysed and compared to those obtained during the laboratory step, in order to define the potential differences given by the in plant production and in situ compaction with roller.

\subsection{Materials}

Two different mixtures for base layers were studied: a traditional HMA and a CRM.

Three materials were used for the recycled mixture: Reclaimed Asphalt Pavement (RAP), Cement (C) and Bituminous Emulsion (EM). A small amount of water was added to the mixture to control the workability and to achieve the maximum dry density during compaction. 
RAP was collected and milled from a motorway asphalt concrete pavement. Later, the material was divided in to three different fractions: coarse RAP 20/40 (20-40 mm), coarse RAP 10/20 (10-20 mm) and fine RAP 0/10 (0-10 mm). Table 1 summarizes the properties of the aged bitumen recovered from the RAP.

As for binder materials, a typical Portland Cement 32.5 and a bituminous emulsion (61\% bitumen content) with a 55 pen grade SBS modified bitumen (Table 2) were adopted.

For HMA mixture, a traditional 50/70 pen grade bitumen was used according to a dosage of $4.3 \%$ by the weight of aggregates.

\section{Laboratory tests and analysis}

\subsection{Mix Design}

CRM was designed on the basis of the characteristics of the available RAP. The aggregate gradations of all the designed mixtures used in this investigation were based on the Fuller's curve.

The amount of each material for CRM are shown in Table 3, while Figure 1 shows the gradation of the two different mixtures.

\subsection{Compaction and workability evaluation}

During this phase the compactability properties and the workability of the two mixtures were evaluated. It was assessed how the high presence of RAP within the mixture, together with bituminous emulsion and cement, could affect its volumetric properties.

Three samples were prepared for each mixture, with a constant compaction pressure of $600 \mathrm{kPa}$, external angle of $1.25^{\circ}$ and 180 revolutions. Figures 2 and 3 show the models of the average compaction curves for each mixture, defined on the basis of the following equation:

$$
\% \rho_{m}=a \cdot \ln (x)+b
$$

Where $\% \rho_{m}$ is the percentage of maximum densification, $a$ is the slope of the compaction curve, $x$ is the number of revolutions and $b$ is the intercept of the regression curve.

Table 4 shows the coefficient used in the former equation and the air voids content of each specimen, determined according to EN 12697-8 standard.

From a comparison between the compaction curves and models, there are not significant differences in terms of workability and maximum density achieved at the end of compaction process. The relative differences for the final density of the two mixtures is less than $1 \%$. As for the air voids content, there are not evident variation between the 
CRM and HMA specimens. Both mixtures are characterised by air voids values very similar to those typically recommended for base layers. These data are significant considering that compactability is one of the weakest point for cold recycling, if compared to traditional hot mixing technique (Gao et al., 2015).

\subsection{Indirect Tensile Strength results analysis}

The static mechanical characterization is conducted by Indirect Tensile Strength (ITS) test both in dry and wet conditions. Three specimens for each mixture were first conditioned at $25{ }^{\circ} \mathrm{C}$ for four hours and then tested according to EN 12697-23 standard. At the same time, other three samples for each mixture were kept into a water bath at $40{ }^{\circ} \mathrm{C}$ for 72 hours and then tested (EN 12697-12). It is well-known that water sensitivity evaluation is essential when studying asphalt recycled mixtures, since this property is directly related to the behaviour and durability of these materials (Dinis-Almeida et al., 2016). The ratio of Indirect Tensile Strength tests in dry and wet conditions can be used to evaluate the water damage, according to equation (2):

$$
I T S R=\frac{I T S_{w e t}}{I T S_{d r y}} \cdot 100
$$

Results are given in Figure 4.

As clearly shown by the histogram, there is a significant difference in terms of ITS resistance between the two mixtures. According to results, as already known, the presence of RAP and bitumen emulsion confer a reduction of ITS values if compared to a high-modulus HMA for base layer $(-43 \%)$. These results are strictly related to the mix design and to the quality of RAP and its aged bitumen (Yan et al., 2014). However, the ITS resistance for CRM is higher than ITS limit (0.35 MPa) imposed by some Italian technical specification for Cold Mix Asphalt for base layer. This data is relevant, considering that the aforementioned limits are related to mixtures made with less than $30 \%$ of RAP.

There is not a substantial difference in the reduction of ITS in wet condition between the two mixtures, even if HMA shows the lower ITSR (89\%) if compared to the RAP mixture (86\%). The reduction of ITS resistance for CRM (13\%) is lower than the limit imposed by the technical standard taken as reference $(<30 \%)$. According to these results, the presence of a high amount of RAP seems not to affect the water susceptibility of the mixture.

\subsection{Indirect Tensile Stiffness Modulus results analysis}

For the mechanical dynamic characterization, a servo-pneumatic testing machine was used. The stiffness modulus was evaluated according to EN 12697-26 standard, in the indirect tensile configuration. Four specimens were tested: to assess the thermal sensitivity of the mixtures tests were performed at 5,20 and $40{ }^{\circ} \mathrm{C}$. The stiffness moduli and the average values for each temperature, are reported in Figure 5. 
The temperature dependency was described using the following analytical model:

$$
\log S=-\alpha \cdot T+\beta
$$

Where $S$ is the stiffness modulus at temperature $T$, and $\alpha$ and $\beta$ are experimental parameters depending on the material. Temperature sensitivity is given by $\alpha$ : higher value means more temperature sensitive material.

As the graphic clearly shows, the stiffness values are higher for HMA at all temperatures. This is probably related to the stiffness of the mastic that comes from the interaction between bitumen and filler. In addition, the traditional mixture here presented, is made of $4.3 \%$ of bitumen on the weight of aggregates. For CRM, on the other hand, only the $2.4 \%$ is new binder. However, the ITSM values for CRM are in line with the limit imposed by the technical standard taken as reference $\left(3000 \mathrm{MPa}\right.$ at $40{ }^{\circ} \mathrm{C}, 4000 \mathrm{MPa}$ at $20{ }^{\circ} \mathrm{C}$ and $5000 \mathrm{MPa}$ at $\left.5{ }^{\circ} \mathrm{C}\right)$. In terms of thermal sensitivity, both the mixtures show the same variation of stiffness at all temperatures. As shown by the temperature dependency equation, the $\alpha$ parameter for the two mixtures are very similar.

\section{In situ tests and analysis}

Once defined the physical and mechanical characteristics of the two mixtures, the further phase of the research program was the realisation of a full-scale trial field. This was built on an existing road without pavement and made of unbound granular material, classified as A1-a according to AASHTO M 145 standard, subject to heavy load traffic due to the proximity of a quarry. This $60 \mathrm{~cm}$ thick layer, characterised by a measured Light Weight Deflectometer Modulus $\left(\mathrm{E}_{\mathrm{LWD}}\right)$ of $70 \mathrm{MPa}$, was used as foundation for the new section. The trial field was divided in two different sections: one realised with the experimental mixture, the other with the traditional one. The new road section constructed on the existing layer, was formed by $15 \mathrm{~cm}$ of CRM or HMA mixture for the base layer and $4 \mathrm{~cm}$ of wearing course made of traditional Asphalt Concrete (Figure 6). Each section was $8 \mathrm{~m}$ wide and $12 \mathrm{~m}$ long.

The road section was voluntary undersized to foster and to accelerate the beginning and development of cracking under the traffic load.

To evaluate and to compare the evolution of the properties of CRM and HMA, in situ test and collection of samples were planned in four dates, corresponding to $0,60,180$ and 365 days of cumulative heavy traffic. At the end of the period, a total of approximately 5000 passes of $42 \mathrm{t}$ dumpers were measured.

\subsection{Volumetric analysis: compaction curve, air voids content and ITS}

A specific quantity of material was taken from the paving screed during the laying process and three samples for each mixture were prepared by gyratory compaction (ASTM D6925), with the same setting and procedures adopted in the laboratory phase. 
Figure 7 and Table 5 show the compaction curve models for CRM and HMA for both laboratory (lab) and trial field (t.f.) phases.

According to the results, all the compaction curves show the same trend. As verified during the laboratory phase, there are not substantial differences between the compaction curves of the CRM and HMA produced in plant. Both the mixtures achieve a good and almost equivalent final density at 180 gyrations (92,5\% for CRM and 93,3\% for HMA). The same relative difference in terms of density is maintained constant during the whole gyratory compaction process. After the laying and the roller compaction, three cores were taken from each section. The air voids content was calculated according to EN 12697-8 standard. Table 6 shows the results.

Air voids content is in line with the compaction curve results: even if there are not significant dissimilarity between the two mixtures, HMA has a lower air voids content. These values are in compliance with those generally obtained after compaction for base layers in Asphalt Concrete. If compared to the volumetric analysis made during the laboratory phase, it can be observed that the air voids content is lightly lower for the core samples. ITS test was also carried out on the same cores, according to EN 12697-23 standard. Figure 8 shows ITS values and the comparison between the values obtained in the laboratory and trial field phase.

The histogram shows a rise in ITS for core samples when compared to laboratory specimens $(+90 \%)$. In this case the ITS values for CRM are very high considering this type of asphalt concrete and similar to those usually identified for common bituminous mixtures.

Those data confirm the value of the mix design and the good paving processes of in plant production, laying and compaction.

\subsection{Development of Stiffness Modulus}

As already mentioned, it was evaluated the development of the stiffness of the two mixtures under traffic load, by taking cores according to a specific timetable. Four date were chosen, corresponding to 0, 60, 180 e 365 days of cumulative passes of trucks. For each repetition, three cores for both mixtures were first conditioned for six hours at 20 ${ }^{\circ} \mathrm{C}$ and then tested in accordance to EN 12697-26 standard in the indirect tensile configuration.

Figure 9 shows the results for cores while data are compared with those obtained during the laboratory phase in Table 7.

From the results analysis it is clear that both the mixtures follow a similar trend in terms of stiffness development. There is a gradual increase in stiffness from day 0 to 60 followed by a progressive reduction until day 365 . The initial rise of the stiffness moduli is probably due to the road pavement settlement given by the traffic load. After the 60th day, a gradual decrease in stiffness values is recorded: it probably marks the beginning of the loss of mechanical properties of 
the material due to the effect of the traffic. For CRM mixture it is recorded a reduction in stiffness of $33 \%$ from day 60 to day 365, while for HMA the same decrease is of $22 \%$. However, even if values are lower when compared to the reference mixture, the stiffness modulus calculated for CRM is acceptable considering the high RAP content, the heavy traffic and the under-designed road section. Furthermore, in addition to the results obtained after ITS tests, data from Table 7 confirm that CRM mix design is effectively reproducible in cold mix plant. The values of stiffness for every core sample taken right after the paving process, are always higher than those recorded for the specimens processed in laboratory.

\section{Discussion and Conclusions}

The aim of the present work was to evaluate the physical and mechanical properties of a cold recycled mixture made with $100 \%$ RAP material together with bituminous emulsion and Portland cement. The experimental program was divided in a laboratory and a trial field phase, in which the properties of the material have been always compared with those registered for a high-modulus Hot Mix Asphalt for base layer, taken as a reference.

According to the experimental results presented in this study, the following conclusion can be drawn for the laboratory phase:

- The presence of $100 \%$ RAP inside the mix does not seem to worsen the compactability of the bituminous mixture. As shown by the compaction curve, according this specific mix design, the high presence of RAP together with bituminous emulsion and cement do not limit the workability of the mixture if compared to the reference HMA. There is not a significant difference in terms of final density and air voids content between the two mixtures.

- As results of static and dynamic mechanical characterization, from ITS and ITSM test, the difference in terms of resistance and stiffness between the two mixture is clear. However, even if CRM shows the lower values, its indirect tensile resistance and stiffness modulus are acceptable and higher than the limits imposed by most common Italian technical specification for Cold Mix Asphalt made of up to $30 \%$ of RAP. In addition, the high presence of RAP within the mix does not modify the water susceptibility of the mixture if compared to traditional HMA, as it is confirmed by ITS test in wet conditions. As for ITSM test, the presence of RAP and bituminous emulsion does not affect the thermal sensitivity of the mixture, which has the same trend registered for the reference HMA. 
The results of the trial field phase were very useful for the evaluation of the feasibility of CRM mix design in a real cold mix plant. On the basis of the data obtained in this second step of the experimental program, the following conclusion can be drawn:

- The gyratory curves obtained after the compaction of the material taken from the paving screed, confirm the results achieved in the laboratory phase. There are not evident differences regarding the volumetric properties of the two mixtures. The analysis of air voids content of the core samples proves the good workability and compactability properties of CRM.

- From ITS and ITSM test, it is confirmed the difference in terms of resistance and stiffness between the experimental and the reference mixture. In this case, the mechanical properties of CRM are considerably higher than those registered during the laboratory characterization. The trends of development of the stiffness moduli for CRM and HMA are the same for the whole period of analysis. The high presence of RAP does not determine an excessive reduction in stiffness after 365 days of cumulative passes of dumpers and trucks.

According to this results, it can be first stated that there is correspondence between the data obtained during the preliminary laboratory characterization and those registered from in situ tests. Thus highlights the validity of the mix design, and the quality of the constituents of the mixture. Furthermore, data also indicates that all the processes, from in plant production to the stated paving operations, have proved to be correct and completely feasible. The mechanical and physical properties of the experimental mixture are strictly related to the mix design and to the quality of RAP, being the step of characterization of this material of crucial importance. Further work is clearly necessary to study the durability and the fatigue performance of CRM mixtures in order to back the conclusions here presented. 


\section{References}

1. Gomez, C., Taboada, H.A. and Espiritu, J.F. (2013). "To be green or not to be green? Ethical tools for sustainability engineering”. $20^{\text {th }}$ ASEE Annual Conference and Exposition; Atlanta, GA, United States.

2. Horvath, A. (2003). "Life-cycle environmental and economic assessment of using recycled materials for asphalt pavements". Technical Report, University of California Transportation Center.

3. Celauro, C., Celauro, B. and Boscaino, G. (2010). "Production of innovative, recycled and high performance asphalt for road pavements". Resources, Conservation \& Recycling, 54, 337-347.

4. Dondi, G., Sangiorgi, C. and Lantieri, C. (2014). "Applying geostatistics to continuous compaction control of construction and demolition materials for road embankments". Journal of Geotechnical and Geoenviromental Engineering, 140 (3).

5. Dondi, G., Pettinari, M., Sangiorgi, C. and Zoorob, S. E. (2013). "Traditional and Dissipated Energy approaches to compare the 2PB and 4PB flexural methodologies on a Warm Mix Asphalt". Construction and Building Materials, 47, 833-839.

6. Sangiorgi, C., Tataranni, P., Simone, A., Vignali, V., Lantieri, C. and Dondi, G. (2016). “Assessment of waste bleaching clay as alternative filler for the production of porous asphalts". Construction and Building Materials, $109,1-7$.

7. Mazzotta, F., Sangiorgi, C., Vignali, V., Lantieri, C. and Dondi, G. (2015). "Rheological characterization of bituminous mastics added with waste bleaching clays". $8^{\text {th }}$ RILEM Symposium on testing and characterization of sustainable and innovative bituminous materials, October 7-9, Ancona, Italy.

8. Chiu, C.T., Hsu, T.H. and Yang, W.F. (2008). "Life cycle assessment on using recycled materials for rehabilitating asphalt pavements". Resources, Conservation \& Recycling, 52, 545-556.

9. Dondi, G., Sangiorgi, C., Lantieri, C., Simone, A., Vignali, V. and Lamperti, R. (2014). Performance evaluation of Construction and Demolition, and other waste materials. $3^{\text {rd }}$ International Conference on Transportation Infrastructure, ICTI 2014; Pisa; Italy.

10. Sangiorgi, C., Lantieri, C. and Dondi, G. (2015). "Construction and demolition waste recycling: an application for road construction". International Journal of Pavement Engineering, 16, 530-537.

11. Dondi, G., Tataranni, P., Pettinari, M., Sangiorgi, C., Simone, A. and Vignali, V. (2014). "Crumb Rubber in Cold Recycled Mixes: comparison between Traditional Crumb Rubber and Cryogenic Crumb Rubber”. Construction and Building Materials, 68, 370-375. 
12. Sangiorgi, C., Tataranni, P., Simone, A., Vignali, V., Lantieri, C. and Dondi, G. (2014). "Waste bleaching clays as fillers in hot bituminous mixtures". Construction and Building Materials, 73, 320-325.

13. Alfonso, M.L., Dinis-Almeida, M., Pereira-de-Oliveira, L.A., Castro-Gomes, J. and Zoorob, S.E. (2016). "Development of a semi-flexible heavy duty pavement surfacing incorporating recycled and waste aggregates - Preliminary study". Construction and Building Materials, 102, 155-161.

14. Pettinari, M., Dondi, G., Sangiorgi, C. and Hededal, O. (2014) "The effect of cryogenic crumb rubber in cold mixes for road pavements". Construction and Building Materials, 63, 249-256.

15. Pettinari, M., Dondi, G., Sangiorgi, C., Petretto, F. (2013) "The use of cryogenic crumb rubber in the cold recycling technique". Airfield and Highway Pavement 2013: Sustainable and Efficient Pavements, Los Angeles, United States, 1088-1099.

16. Jacobson, T. and Hornwall, F. (2000). "Cold recycling of asphalt pavement-mix in plant". Eurasphalt \& Eurobitume 2000, Barcelona, Spain, 2, 260-267.

17. Pettinari, M. and Simone, A. (2015). "Effect of crumb rubber gradation on a rubberized cold recycled mixture for road pavements". Material \& Design, 85, 598-606.

18. Dondi, G., Mazzotta, F., Sangiorgi, C., Pettinari, M., Simone, A., Vignali, V. and Tataranni, P. (2014). "Influence of cement and limestone filler on the rheological properties of mastic in cold bituminous recycled mixtures". $3^{\text {rd }}$ International Conference on Transportation Infrastructures, ITCI 2014, April 22-25, Pisa, Italy.

19. Silva, H.M.R.D, Oliveira, J.R.M., and Jesus, C.M.G. (2012). "Are totally recycled hot mix asphalts a sustainable alternative for road paving?”. Resources, Conservation \& Recycling, 60, 38-48.

20. Simone, A., Vignali, V. and Lantieri, C. (2012). "A new "frugal" approach to road maintenance: $100 \%$ recycling of a deteriorated flexible pavement". $7^{\text {th }}$ International Conference on Maintenance and Rehabilitation of Pavements and Technological Control, MAIREPAV 2012, New Zealand.

21. Abreu, L.P.F., Oliveira, J.R.M., Silva, H.M.R.D and Fonseca, P.V. (2015). "Recycled asphalt mixtures produced with high percentage of different waste material". Construction and Building Materials, 84, $230-238$.

22. Gao, L., Ni, F., Luo, H. and Charmot, S. (2015). "Characterization of air voids in cold in-place recycling mixtures using X-ray computed tomography”. Construction and Building Materials, 84, 429-436.

23. Dinis-Almeida, M., Castro-Gomes, J., Sangiorgi, C., Zoorob, S.E. and Afonso, M.L. (2016). "Performance of Warm Mix Recycled Asphalt containing up to 100\% RAP”. Construction and Building Materials, 112, 1-6. 
24. Yan, J., Zhu, H., Zhang, Z., Gao, L. and Charmot, S. (2014). "The theoretical analysis of the RAP aged asphalt influence on the performance of asphalt emulsion cold recycled mixes". Construction and Building Materials, $71,444-450$. 


\section{Tables with captions}

\begin{tabular}{lcccc}
\hline & Unit & RAP 20/40 & RAP 10/20 & RAP 0/10 \\
\hline \% Binder & $\%$ & 3.77 & 3.82 & 6.19 \\
Penetration @ 25 ${ }^{\circ} \mathrm{C}$ & $d m m$ & 9 & 8 & 7 \\
Soft.Point & ${ }^{\circ} \mathrm{C}$ & 74.7 & 76.1 & 79.7 \\
Dynamic Visc. @ 60 ${ }^{\circ} \mathrm{C}$ & $\mathrm{Pa} \cdot \mathrm{s}$ & 52265 & 58051 & 95219 \\
Heptane insolubles & $\%$ & 41.5 & 40.3 & 38.7 \\
\hline
\end{tabular}

Table 1. Properties of the aged asphalt binder from RAP.

\begin{tabular}{lccl}
\hline \multicolumn{4}{c}{ Characteristics of the cationic emulsion } \\
\hline Characteristics & Unit & Result & Standard \\
\hline Water content & $\%$ & 39 & EN 1428 \\
pH value & $\circ$ & 4 & EN 12850 \\
Settling tendency @ 7 days & $\%$ & 6 & EN 12847 \\
\hline \multicolumn{4}{c}{ Characteristics of the extracted bitumen } \\
\hline Penetration & $d m m$ & 55 & EN 1426 \\
Softening point & ${ }^{\circ} \mathrm{C}$ & 62 & EN 1427 \\
Fraass breaking point & ${ }^{\circ} \mathrm{C}$ & -16 & EN 12593 \\
\hline
\end{tabular}

Table 2. Properties of the bitumen emulsion.

\begin{tabular}{lcc}
\hline \multicolumn{1}{c}{ Material } & Density $\left(\mathbf{g} / \mathbf{c m}^{3}\right)$ & Mixture \\
\hline RAP 20-40 & 2.62 & $14.0 \%$ \\
RAP 10-20 & 2.62 & $25.0 \%$ \\
RAP 0-10 & 2.63 & $55.0 \%$ \\
Filler & 2.66 & $4.0 \%$ \\
Cement & 2.95 & $2.0 \%$ \\
\hline Bitumen Emulsion $($ EM) & $1.04\left(\right.$ at $\left.25^{\circ} \mathrm{C}\right)$ & $4.0 \%$ \\
Additional Water & $0.99\left(\right.$ at $\left.25^{\circ} \mathrm{C}\right)$ & $0.9 \%$ \\
\hline
\end{tabular}

Table 3. Designation and composition of CRM.

\begin{tabular}{cccc}
\hline Mixture & $\boldsymbol{a}$ & $\boldsymbol{b}$ & $\boldsymbol{V a}(\boldsymbol{\%})$ \\
\hline CRM_1 & 3.223 & 76.371 & 7.1 \\
CRM_2 & 3.354 & 75.901 & 6.8 \\
CRM_3 & 3.351 & 75.722 & 7.0 \\
Model CRM & 3.309 & 75.998 & \\
\hline HMA_1 & 3.182 & 77.050 & 6.5 \\
HMA_2 & 3.301 & 76.576 & 6.4 \\
HMA_3 & 3.300 & 76.515 & 6.5 \\
Model HMA & 3.261 & 76.714 & \\
\hline model equation: $\boldsymbol{y}=\boldsymbol{a} \cdot \boldsymbol{l n}(\boldsymbol{x})+\boldsymbol{b}$ \\
\hline
\end{tabular}

Table 4. Gyratory compaction curves models and air voids content. 


\begin{tabular}{ccc}
\hline Mixture & $\boldsymbol{a}$ & $\boldsymbol{b}$ \\
\hline Model CRM lab & 3.309 & 75.998 \\
Model HMA lab & 3.261 & 76.714 \\
Model CRM t.f. & 3.341 & 74.759 \\
Model HMA t.f. & 3.476 & 75.231 \\
\hline model equation: $\boldsymbol{y}=\boldsymbol{a} \cdot \boldsymbol{l n}(\boldsymbol{x})+\boldsymbol{b}$ \\
\hline
\end{tabular}

Table 5. Gyratory compaction curves models for CRM and HMA after laboratory and trial field compaction.

\begin{tabular}{cc}
\hline Mixture & Air voids (\%) \\
\hline CRM 1 & 7.1 \\
CRM 2 & 6.3 \\
CRM 3 & 6.3 \\
Avg. CRM & 6.6 \\
\hline HMA 1 & 5.8 \\
HMA 2 & 6.3 \\
HMA 3 & 6.0 \\
Avg. HMA & 6.0 \\
\hline
\end{tabular}

Table 6. Air voids content for CRM and HMA cores.

\begin{tabular}{|c|c|c|c|c|c|c|c|c|c|c|}
\hline \multicolumn{11}{|c|}{ Indirect Tensile Stiffness Modulus (MPa) @ $20^{\circ} \mathrm{C}$} \\
\hline Mixture & \multicolumn{2}{|c|}{ Lab analysis } & \multicolumn{2}{|c|}{0} & \multicolumn{2}{|c|}{60 days } & \multicolumn{2}{|c|}{180 days } & \multicolumn{2}{|c|}{365 days } \\
\hline \multirow{5}{*}{ CRM } & CRM 1 & 4486 & CRM 0.1 & 4998 & CRM 1.1 & 5795 & CRM 2.1 & 4689 & CRM 3.1 & 4002 \\
\hline & CRM 2 & 4320 & CRM 0.2 & 5158 & CRM 1.2 & 5935 & CRM 2.2 & 4587 & CRM 3.2 & 3987 \\
\hline & CRM 3 & 4288 & CRM 0.3 & 5369 & CRM 1.3 & 5888 & CRM 2.3 & 4487 & CRM 3.3 & 3901 \\
\hline & CRM 4 & 4698 & & & & & & & & \\
\hline & $\begin{array}{l}\text { Avg. } \\
\text { CRM }\end{array}$ & 4448 & $\begin{array}{l}\text { Avg. } \\
\text { CRM }\end{array}$ & 5175 & $\begin{array}{l}\text { Avg. } \\
\text { CRM }\end{array}$ & 5873 & $\begin{array}{l}\text { Avg. } \\
\text { CRM }\end{array}$ & 4588 & $\begin{array}{l}\text { Avg. } \\
\text { CRM }\end{array}$ & 3963 \\
\hline \multirow{5}{*}{ HMA } & HMA 1 & 9898 & HMA 0.1 & 9788 & HMA 1.1 & 10780 & HMA 2.1 & 9802 & HMA 3.1 & 8512 \\
\hline & HMA 2 & 10083 & HMA 0.2 & 9801 & HMA 1.2 & 10089 & HМА 2.2 & 9471 & HMA 3.2 & 8019 \\
\hline & HMA 3 & 9425 & НМА 0.3 & 9925 & HМА 1.3 & 10945 & HMA 2.3 & 9678 & HMA 3.3 & 8308 \\
\hline & HМА 4 & 9645 & & & & & & & & \\
\hline & $\begin{array}{l}\text { Avg. } \\
\text { HMA }\end{array}$ & 9763 & $\begin{array}{l}\text { Avg. } \\
\text { HMA }\end{array}$ & 9838 & $\begin{array}{l}\text { Avg. } \\
\text { HMA }\end{array}$ & 10605 & $\begin{array}{l}\text { Avg. } \\
\text { HMA }\end{array}$ & 9650 & $\begin{array}{l}\text { Avg. } \\
\text { HMA }\end{array}$ & 8280 \\
\hline
\end{tabular}

Table 7. ITSM test results at $20{ }^{\circ} \mathrm{C}$ from laboratory and trial field phase. 


\section{Captions List}

Table 1. Properties of the aged asphalt binder from RAP.

Table 2. Properties of the bitumen emulsion.

Table 3. Designation and composition of CRM.

Table 4. Gyratory compaction curves models and air voids content.

Table 5. Gyratory compaction curves models for CRM and HMA after laboratory and trial field compaction.

Table 6. Air voids content for CRM and HMA cores.

Table 7. ITSM test results at $20{ }^{\circ} \mathrm{C}$ from laboratory and trial field phase.

Figure 1. CRM and HMA gradations.

Figure 2. CRM gyratory compaction curves (left); HMA gyratory compaction curves (right).

Figure 3. Comparison between CRM and HMA compaction curves models.

Figure 4. Indirect Tensile Strength results in dry and wet conditions.

Figure 5. Indirect Tensile Stiffness Modulus results: total and average values at 5, 20 and $40{ }^{\circ} \mathrm{C}$.

Figure 6. Trial field paving operations: layng of CRM (left) and compaction with rollers (right).

Figure 7. Compaction curve models for CRM and HMA after laboratory and trial field compaction.

Figure 8. ITS resistance for CRM and HMA after laboratory and trial field compaction.

Figure 9. ITSM test results at $0,60,180$ and 365 days of cumulative traffic. 


\section{Figures with captions}

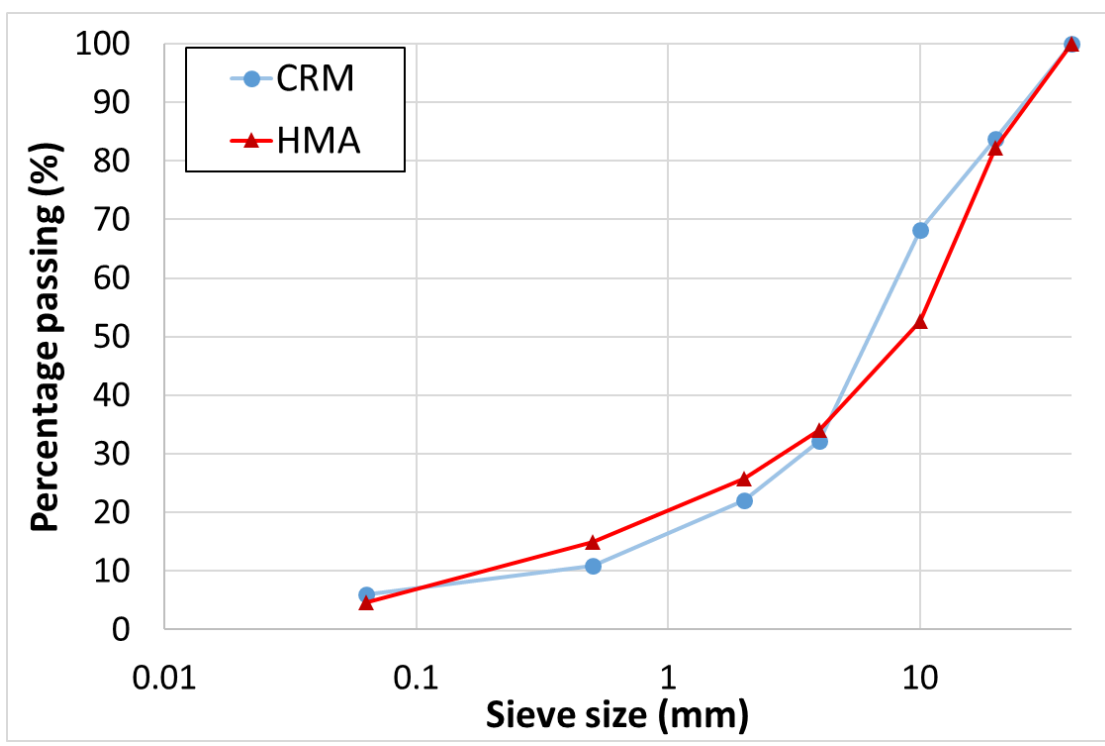

Figure 1. CRM and HMA gradations.

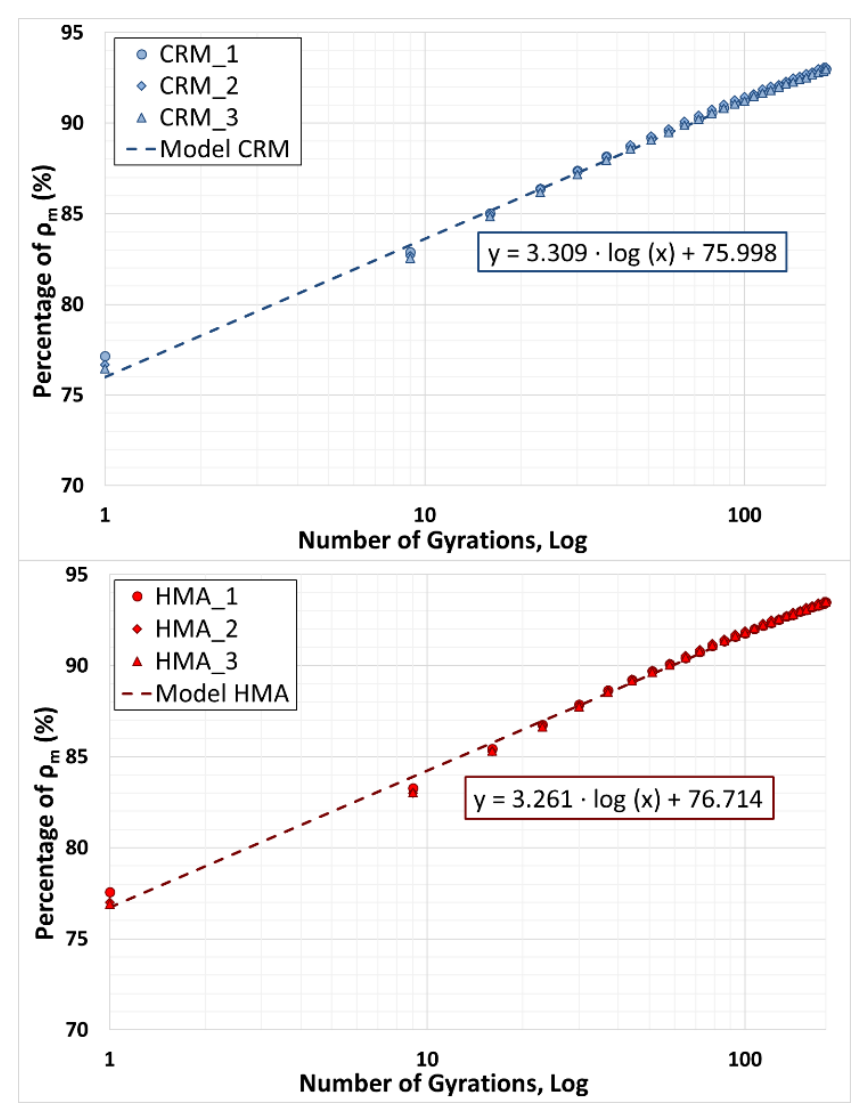

Figure 2. CRM gyratory compaction curves (left); HMA gyratory compaction curves (right). 


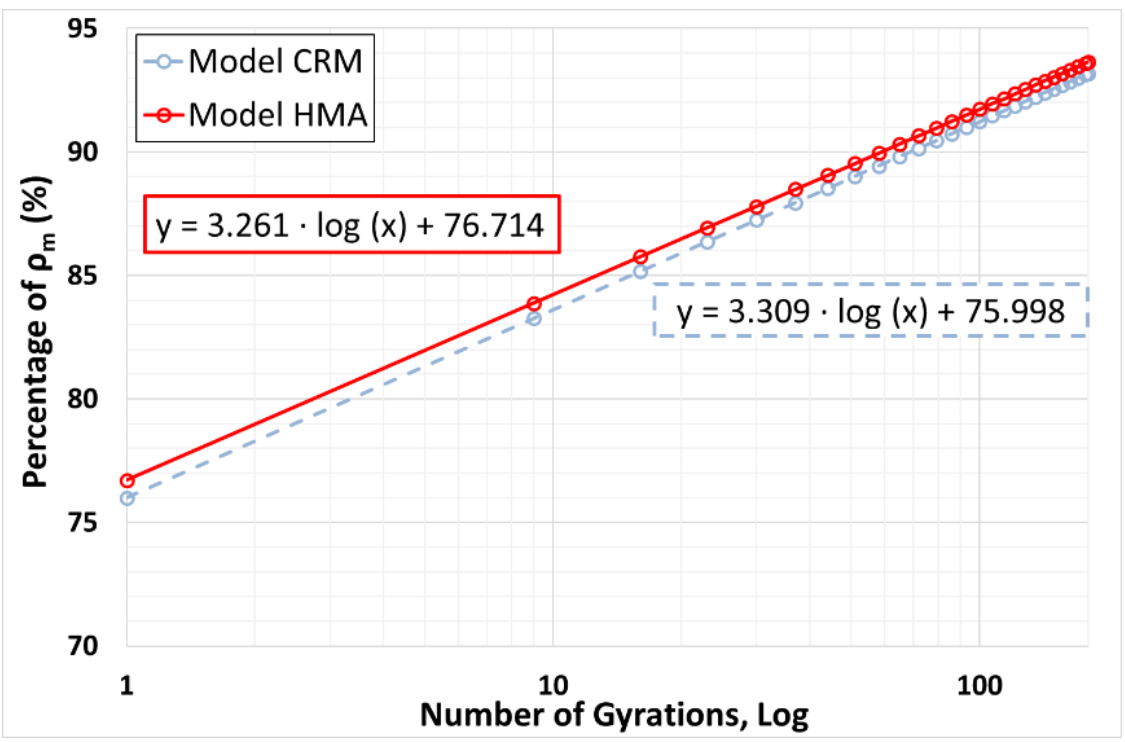

Figure 3. Comparison between CRM and HMA compaction curves models.

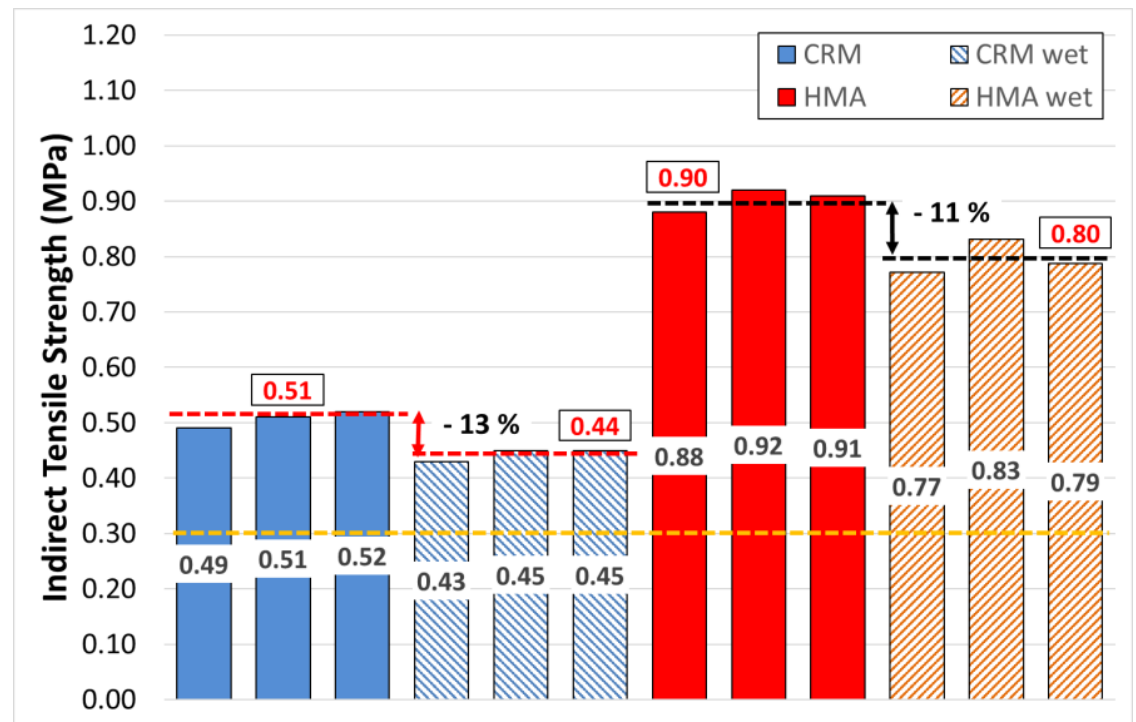

Figure 4. Indirect Tensile Strength results in dry and wet conditions. 


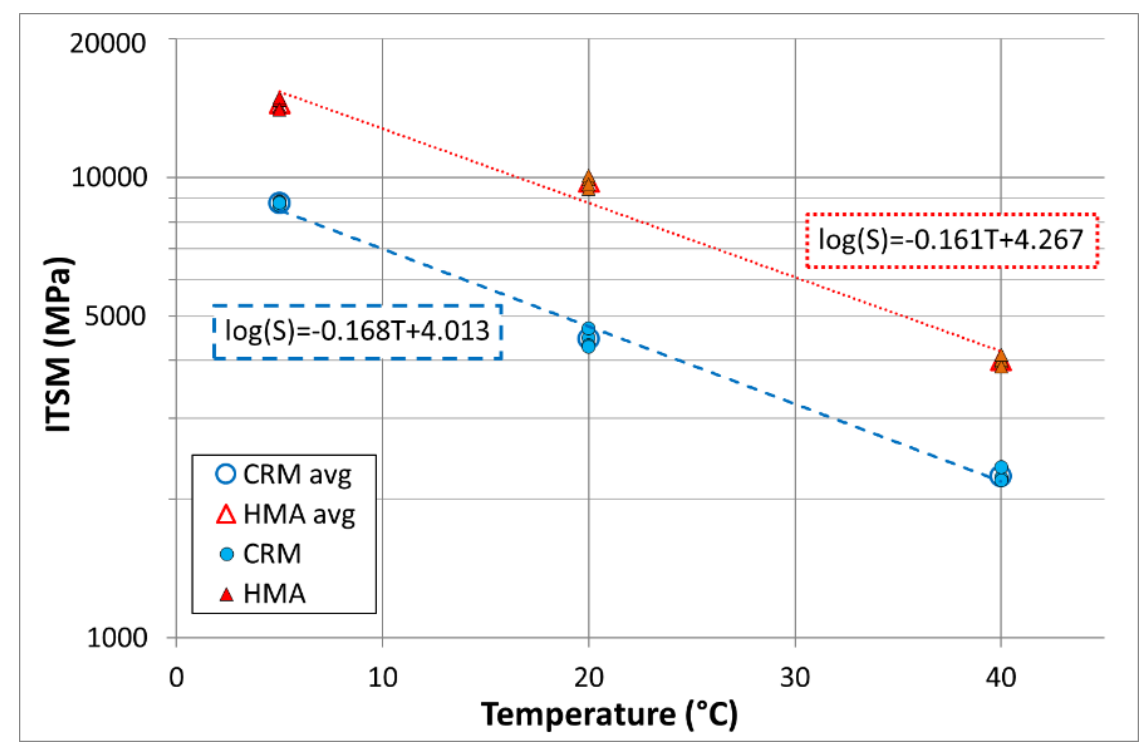

Figure 5. Indirect Tensile Stiffness Modulus results: total and average values at 5, 20 and $40{ }^{\circ} \mathrm{C}$.

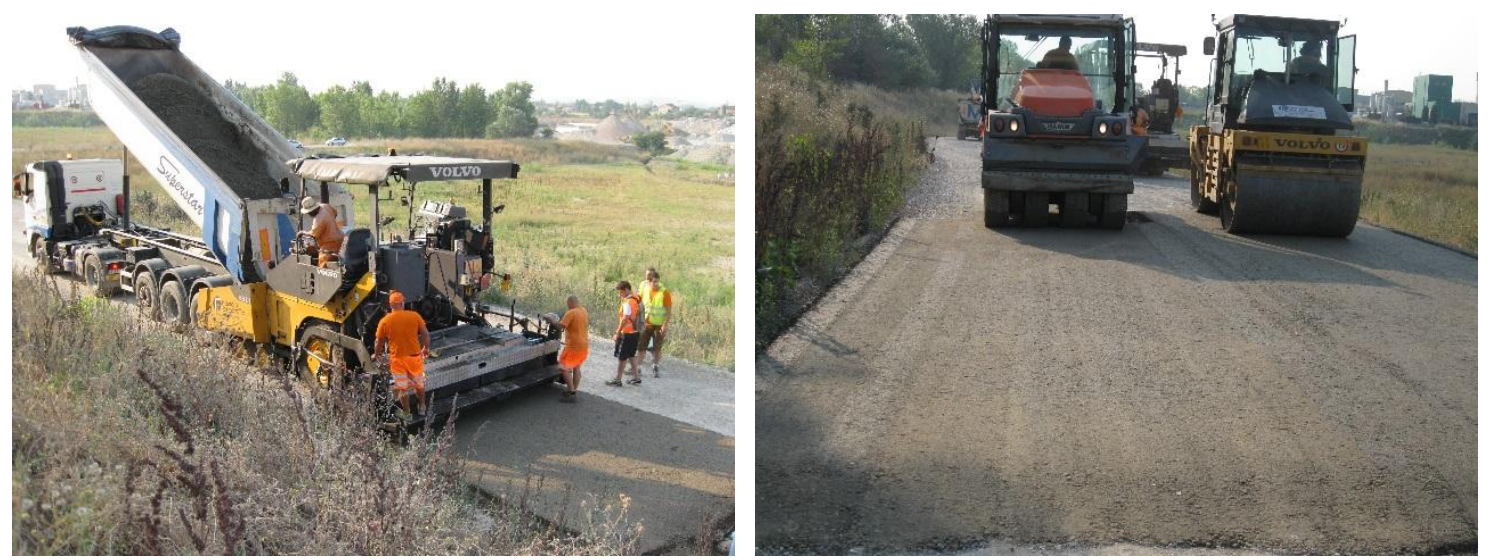

Figure 6. Trial field paving operations: laying of CRM (left) and compaction with rollers (right).

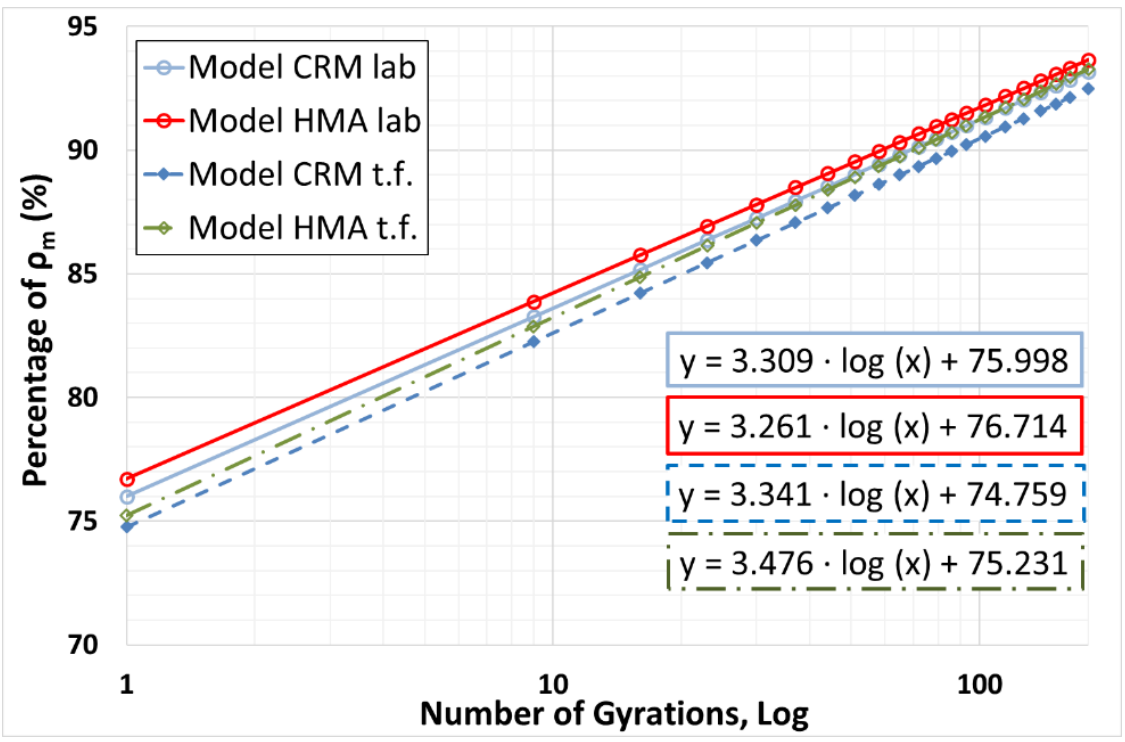

Figure 7. Compaction curve models for CRM and HMA after laboratory and trial field compaction. 


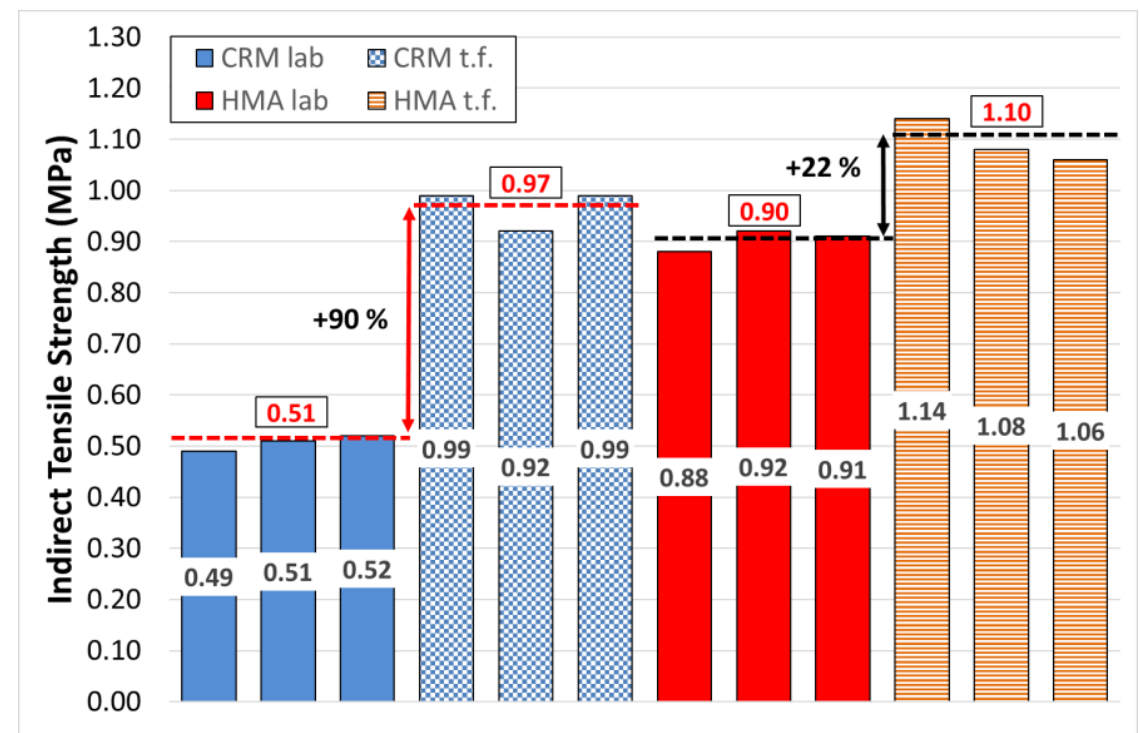

Figure 8. ITS resistance for CRM and HMA after laboratory and trial field compaction.

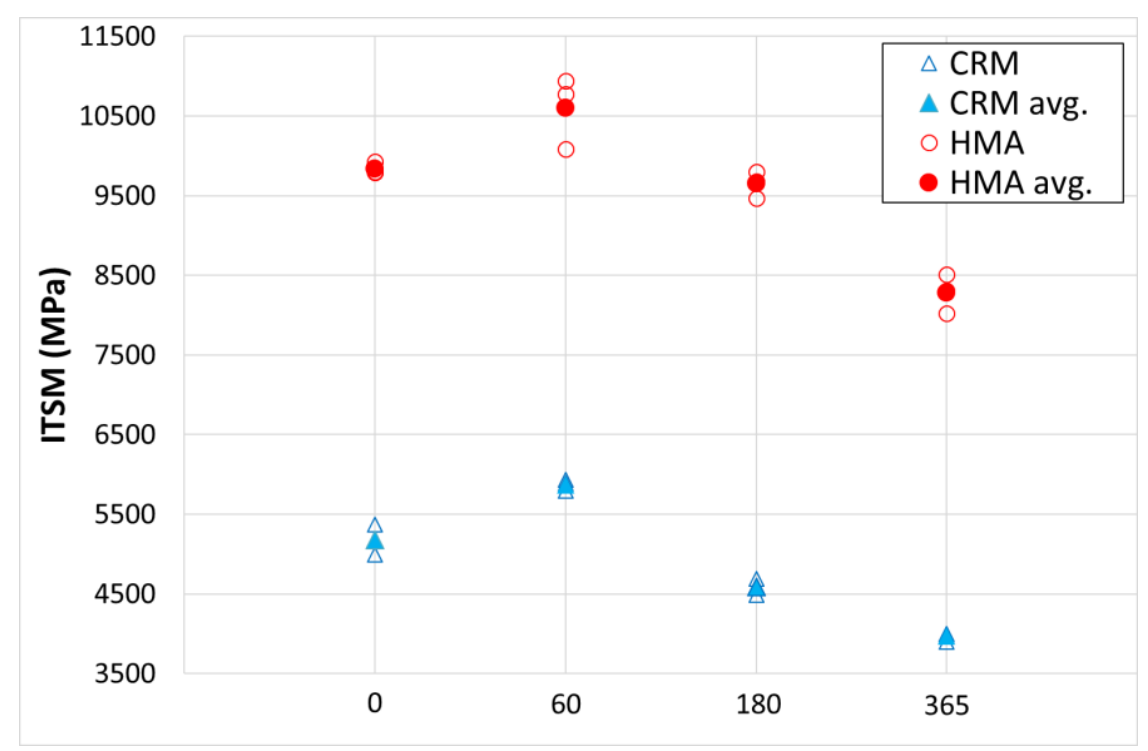

Figure 9. ITSM test results at $0,60,180$ and 365 days of cumulative traffic. 
Figures and Tables with captions

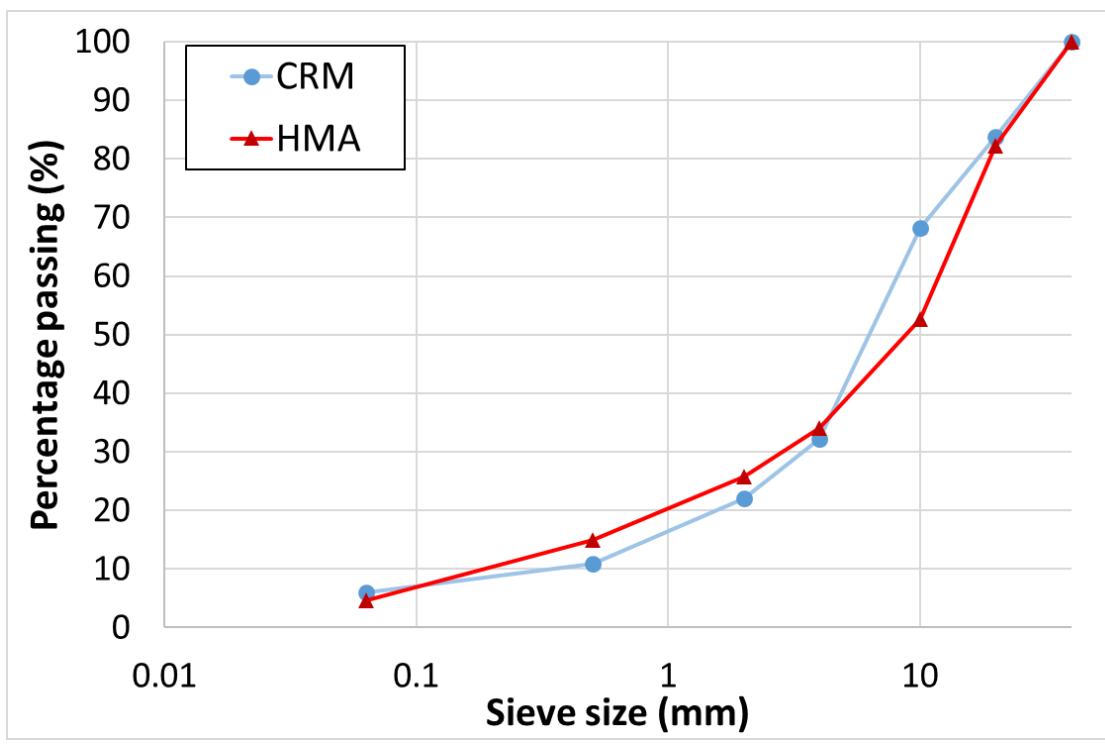

Figure 1. CRM and HMA gradations.

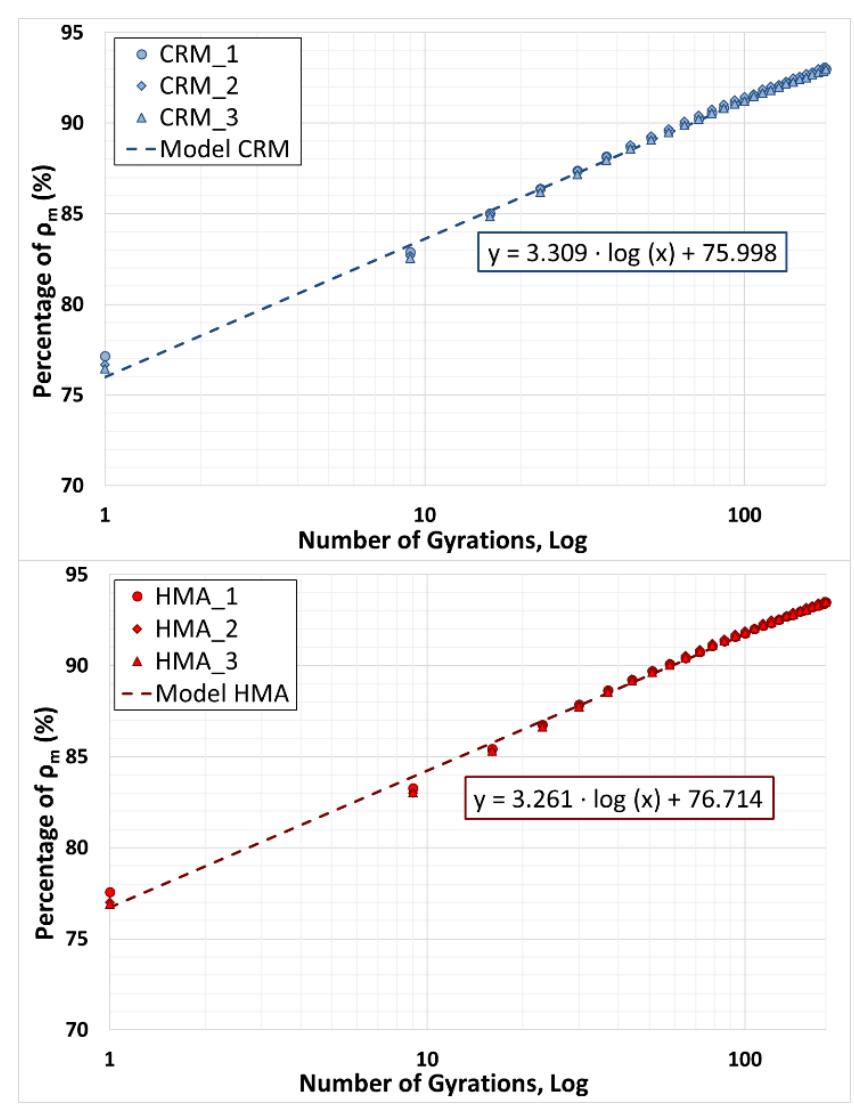

Figure 2. CRM gyratory compaction curves (left); HMA gyratory compaction curves (right). 


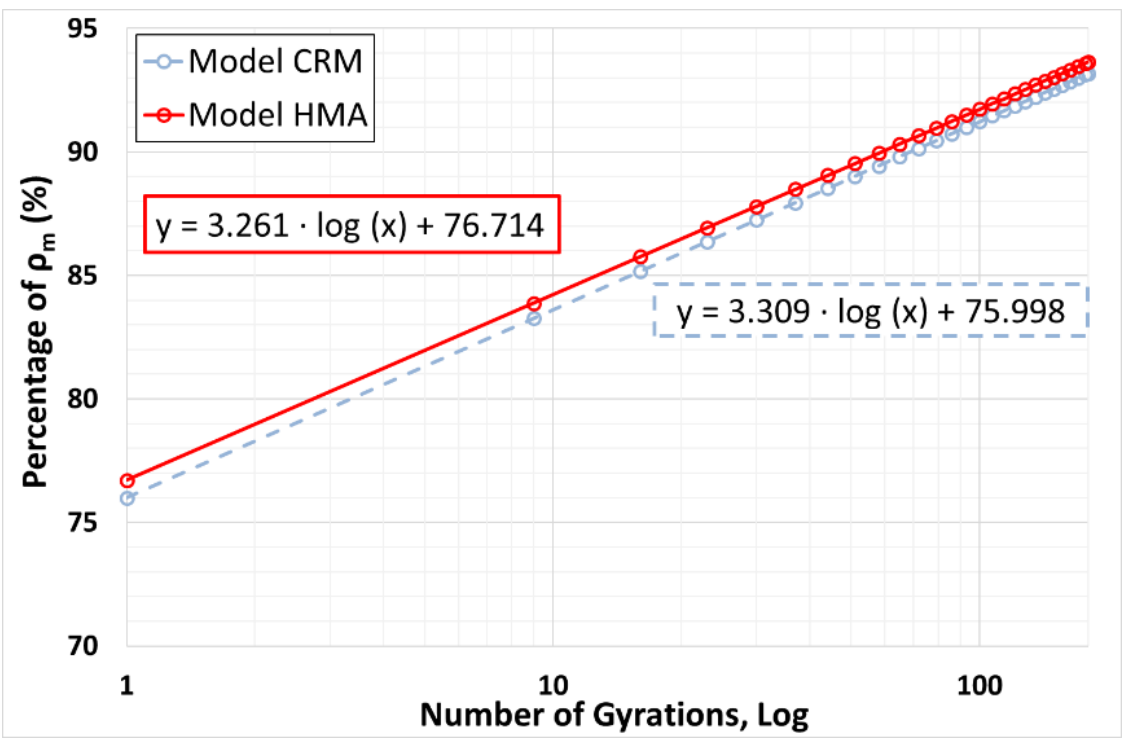

Figure 3. Comparison between CRM and HMA compaction curves models.

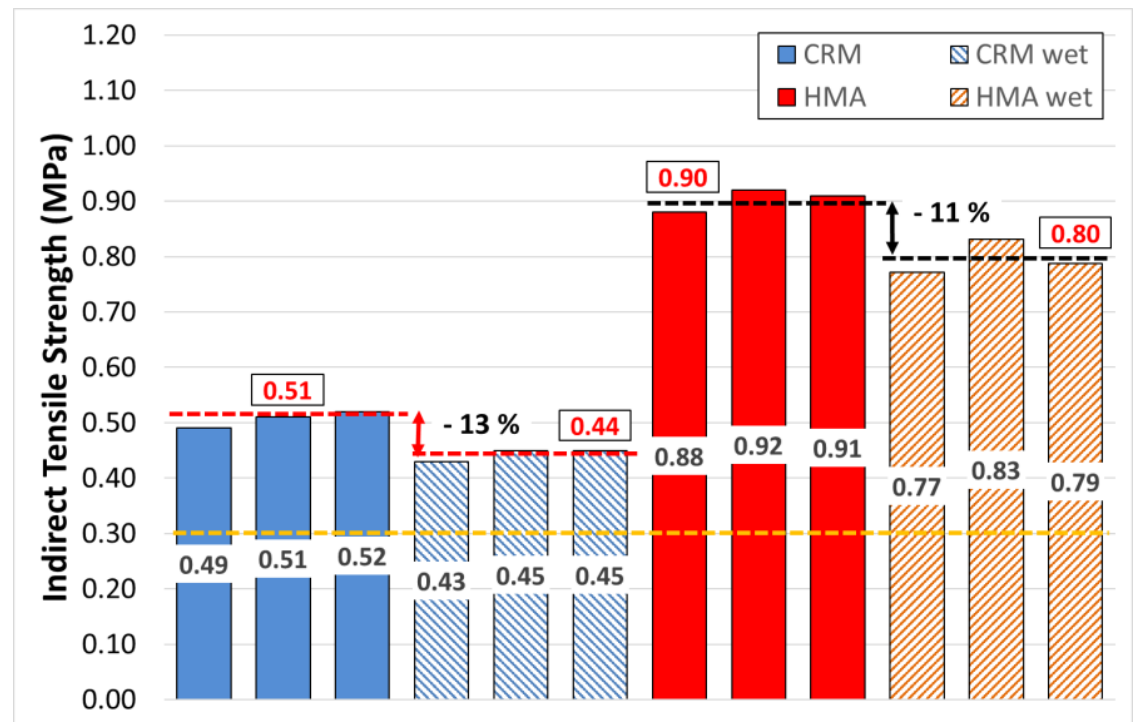

Figure 4. Indirect Tensile Strength results in dry and wet conditions. 


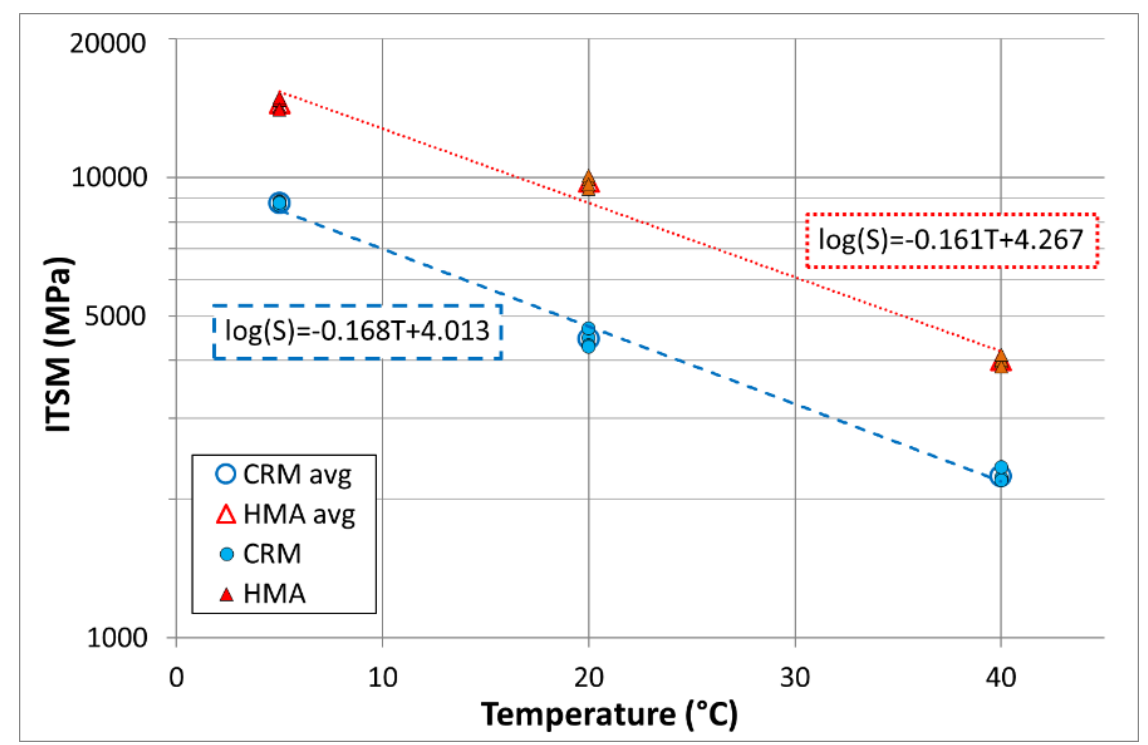

Figure 5. Indirect Tensile Stiffness Modulus results: total and average values at 5, 20 and $40{ }^{\circ} \mathrm{C}$.

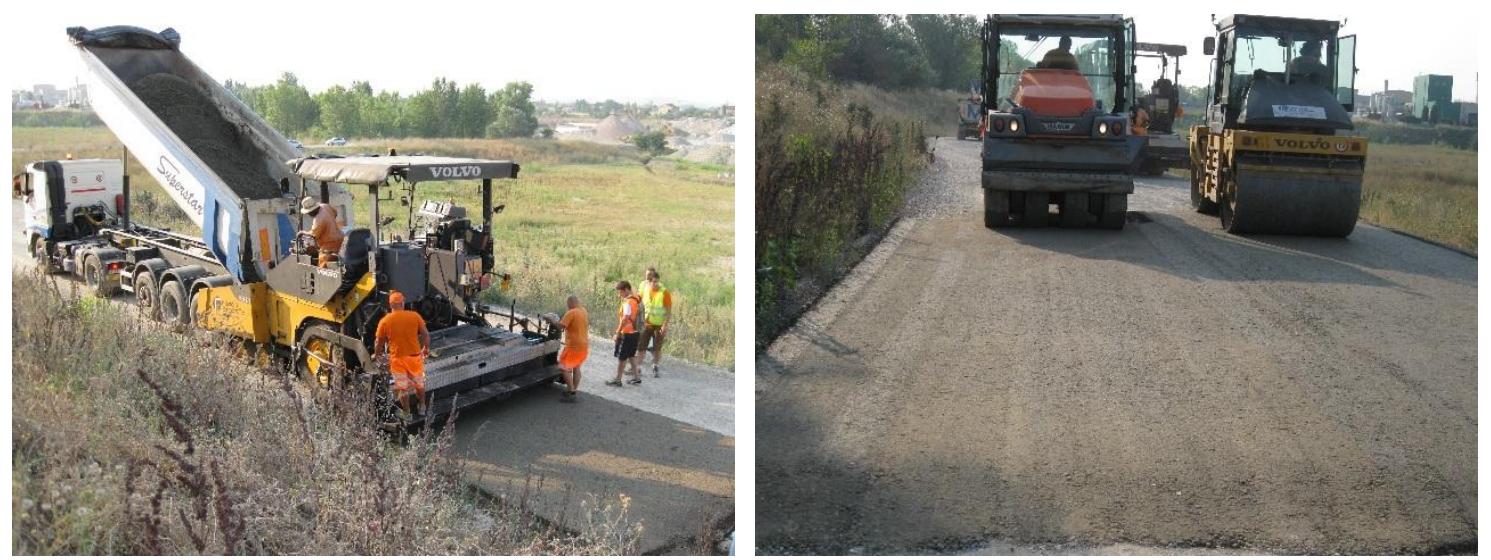

Figure 6. Trial field paving operations: laying of CRM (left) and compaction with rollers (right).

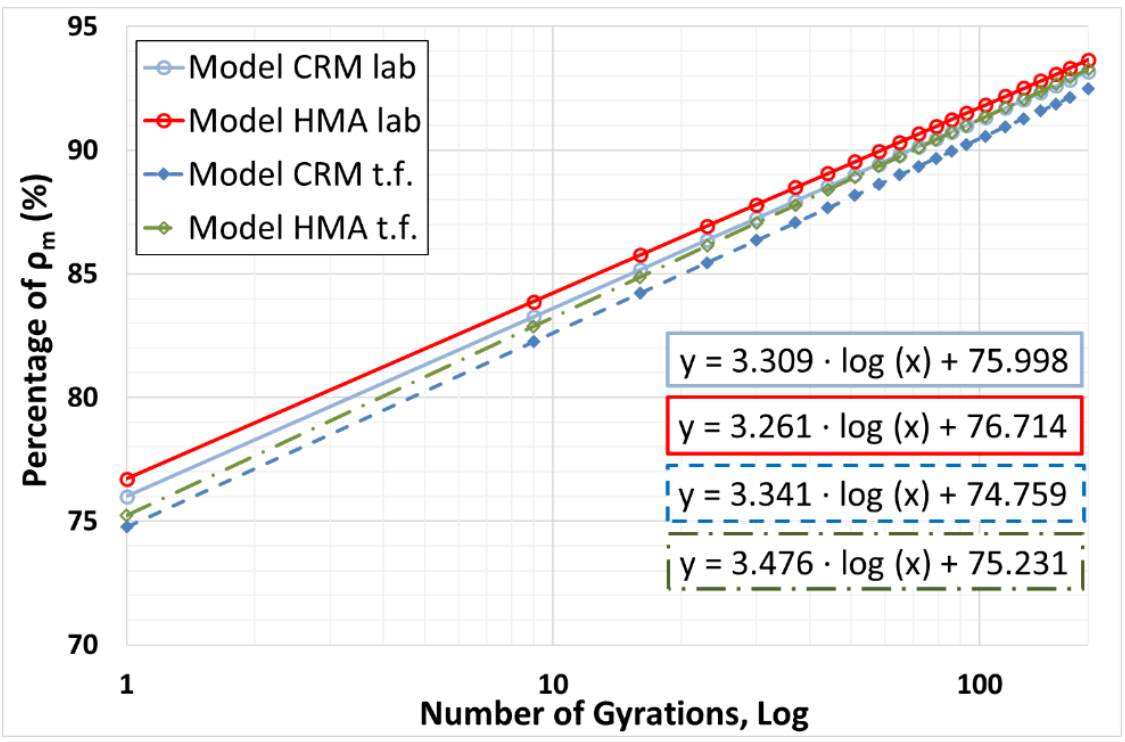

Figure 7. Compaction curve models for CRM and HMA after laboratory and trial field compaction. 


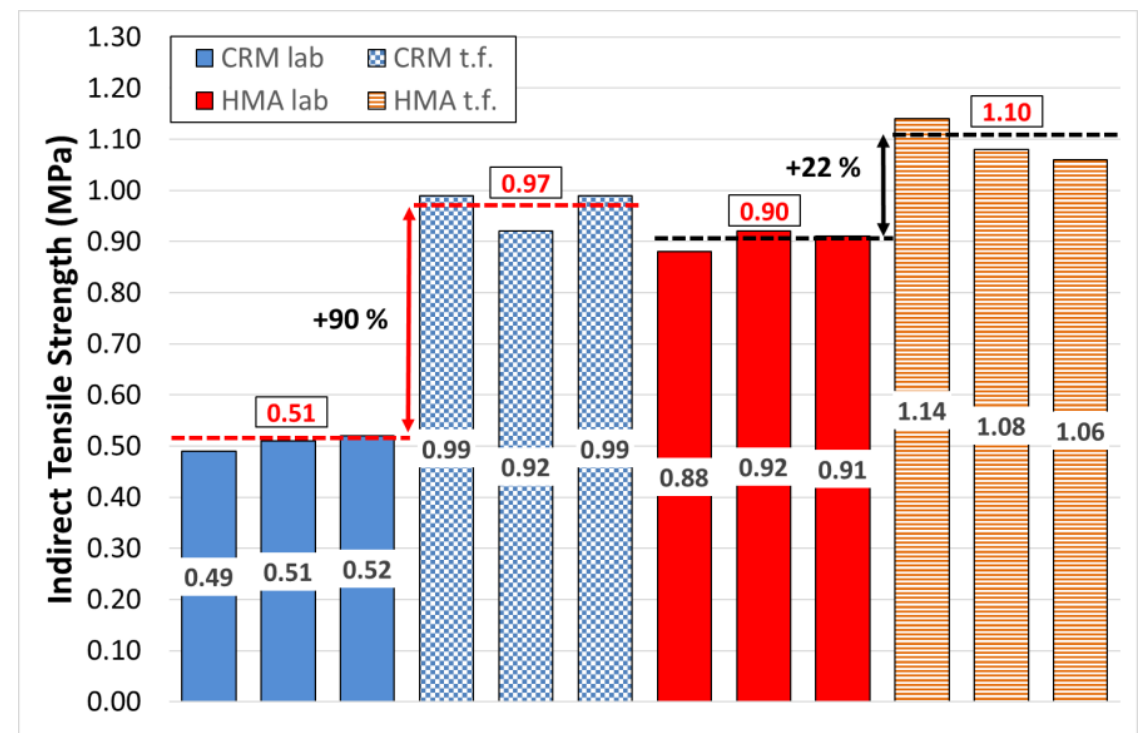

Figure 8. ITS resistance for CRM and HMA after laboratory and trial field compaction.

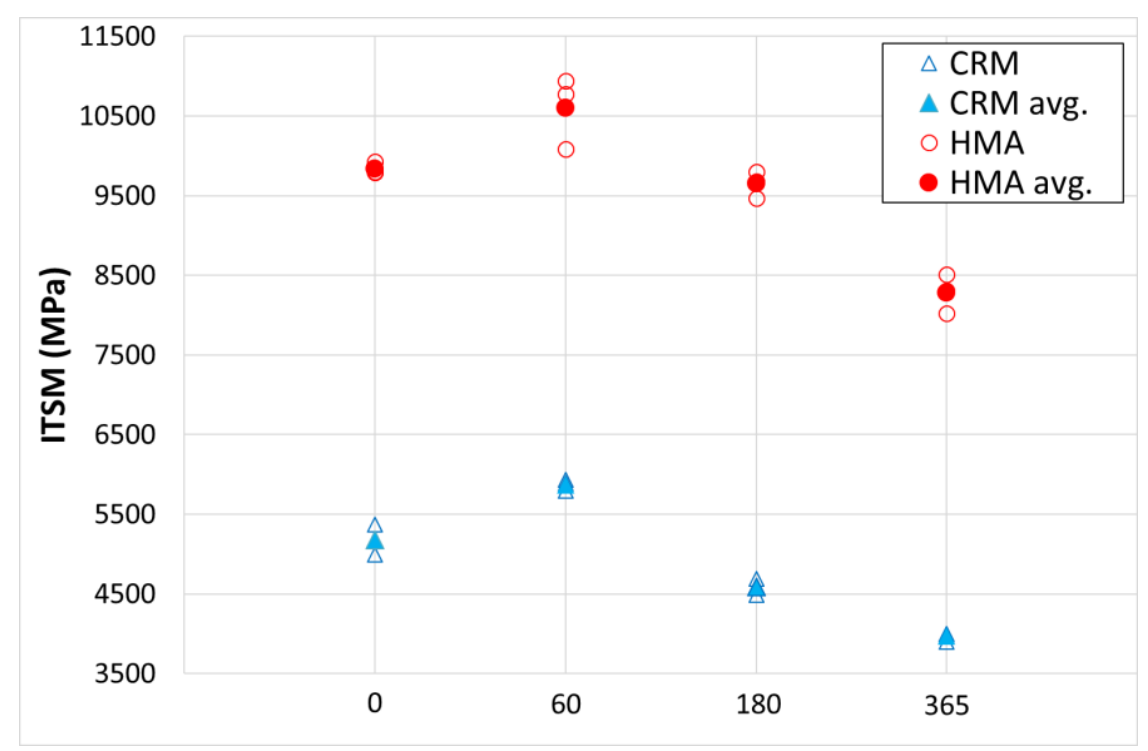

Figure 9. ITSM test results at $0,60,180$ and 365 days of cumulative traffic. 


\begin{tabular}{lcccc}
\hline & Unit & RAP 20/40 & RAP 10/20 & RAP 0/10 \\
\hline \% Binder & $\%$ & 3.77 & 3.82 & 6.19 \\
Penetration @ 25 ${ }^{\circ} \mathrm{C}$ & $d m m$ & 9 & 8 & 7 \\
Soft.Point & ${ }^{\circ} \mathrm{C}$ & 74.7 & 76.1 & 79.7 \\
Dynamic Visc. @ 60 ${ }^{\circ} \mathrm{C}$ & $\mathrm{Pa} \cdot \mathrm{s}$ & 52265 & 58051 & 95219 \\
Heptane insolubles & $\%$ & 41.5 & 40.3 & 38.7 \\
\hline
\end{tabular}

Table 1. Properties of the aged asphalt binder from RAP.

\begin{tabular}{lccl}
\hline \multicolumn{4}{c}{ Characteristics of the cationic emulsion } \\
\hline Characteristics & Unit & Result & Standard \\
\hline Water content & $\%$ & 39 & EN 1428 \\
pH value & $\circ$ & 4 & EN 12850 \\
Settling tendency @ 7 days & $\%$ & 6 & EN 12847 \\
\hline \multicolumn{4}{c}{ Characteristics of the extracted bitumen } \\
\hline Penetration & ${ }^{\circ} \mathrm{dmm}$ & 55 & EN 1426 \\
Softening point & ${ }^{\circ} \mathrm{C}$ & 62 & EN 1427 \\
Fraass breaking point & ${ }^{\circ} \mathrm{C}$ & -16 & EN 12593 \\
\hline
\end{tabular}

Table 2. Properties of the bitumen emulsion.

\begin{tabular}{lcc}
\hline \multicolumn{1}{c}{ Material } & Density $\left(\mathbf{g} / \mathbf{c m}^{3}\right)$ & Mixture \\
\hline RAP 20-40 & 2.62 & $14.0 \%$ \\
RAP 10-20 & 2.62 & $25.0 \%$ \\
RAP 0-10 & 2.63 & $55.0 \%$ \\
Filler & 2.66 & $4.0 \%$ \\
Cement & 2.95 & $2.0 \%$ \\
\hline Bitumen Emulsion $($ EM) & $1.04\left(\right.$ at $\left.25^{\circ} \mathrm{C}\right)$ & $4.0 \%$ \\
Additional Water & $0.99\left(\right.$ at $\left.25^{\circ} \mathrm{C}\right)$ & $0.9 \%$ \\
\hline
\end{tabular}

Table 3. Designation and composition of CRM.

\begin{tabular}{cccc}
\hline Mixture & $\boldsymbol{a}$ & $\boldsymbol{b}$ & $\boldsymbol{V a}(\boldsymbol{\%})$ \\
\hline CRM_1 & 3.223 & 76.371 & 7.1 \\
CRM_2 & 3.354 & 75.901 & 6.8 \\
CRM_3 & 3.351 & 75.722 & 7.0 \\
Model CRM & 3.309 & 75.998 & \\
\hline HMA_1 & 3.182 & 77.050 & 6.5 \\
HMA_2 & 3.301 & 76.576 & 6.4 \\
HMA_3 & 3.300 & 76.515 & 6.5 \\
Model HMA & 3.261 & 76.714 & \\
\hline \multicolumn{4}{c}{ model equation: $\boldsymbol{y}=\boldsymbol{a} \cdot \boldsymbol{l n}(\boldsymbol{x})+\boldsymbol{b}$} \\
\hline
\end{tabular}

Table 4. Gyratory compaction curves models and air voids content.

\begin{tabular}{ccc}
\hline Mixture & $\boldsymbol{a}$ & $\boldsymbol{b}$ \\
\hline Model CRM lab & 3.309 & 75.998 \\
Model HMA lab & 3.261 & 76.714 \\
Model CRM t.f. & 3.341 & 74.759 \\
Model HMA t.f. & 3.476 & 75.231 \\
\hline model equation: $\boldsymbol{y}=\boldsymbol{a} \cdot \boldsymbol{l n}(\boldsymbol{x})+\boldsymbol{b}$ \\
\hline
\end{tabular}

Table 5. Gyratory compaction curves models for CRM and HMA after laboratory and trial field compaction. 


\begin{tabular}{cc}
\hline Mixture & Air voids (\%) \\
\hline CRM 1 & 7.1 \\
CRM 2 & 6.3 \\
CRM 3 & 6.3 \\
Avg. CRM & 6.6 \\
\hline HMA 1 & 5.8 \\
HMA 2 & 6.3 \\
HMA 3 & 6.0 \\
Avg. HMA & 6.0 \\
\hline
\end{tabular}

Table 6. Air voids content for CRM and HMA cores.

\begin{tabular}{|c|c|c|c|c|c|c|c|c|c|c|}
\hline \multicolumn{11}{|c|}{ Indirect Tensile Stiffness Modulus (MPa) @ 20 ${ }^{\circ} \mathrm{C}$} \\
\hline Mixture & \multicolumn{2}{|c|}{ Lab analysis } & \multicolumn{2}{|c|}{0} & \multicolumn{2}{|c|}{60 days } & \multicolumn{2}{|c|}{180 days } & \multicolumn{2}{|c|}{365 days } \\
\hline \multirow{5}{*}{ CRM } & CRM 1 & 4486 & CRM 0.1 & 4998 & CRM 1.1 & 5795 & CRM 2.1 & 4689 & CRM 3.1 & 4002 \\
\hline & CRM 2 & 4320 & CRM 0.2 & 5158 & CRM 1.2 & 5935 & CRM 2.2 & 4587 & CRM 3.2 & 3987 \\
\hline & CRM 3 & 4288 & CRM 0.3 & 5369 & CRM 1.3 & 5888 & CRM 2.3 & 4487 & CRM 3.3 & 3901 \\
\hline & CRM 4 & 4698 & & & & & & & & \\
\hline & $\begin{array}{l}\text { Avg. } \\
\text { CRM }\end{array}$ & 4448 & $\begin{array}{l}\text { Avg. } \\
\text { CRM }\end{array}$ & 5175 & $\begin{array}{l}\text { Avg. } \\
\text { CRM }\end{array}$ & 5873 & $\begin{array}{l}\text { Avg. } \\
\text { CRM }\end{array}$ & 4588 & $\begin{array}{l}\text { Avg. } \\
\text { CRM }\end{array}$ & 3963 \\
\hline \multirow{5}{*}{ HMA } & HMA 1 & 9898 & НМА 0.1 & 9788 & HМА 1.1 & 10780 & НМА 2.1 & 9802 & НMA 3.1 & 8512 \\
\hline & HMA 2 & 10083 & HMA 0.2 & 9801 & HMA 1.2 & 10089 & HMA 2.2 & 9471 & HМА 3.2 & 8019 \\
\hline & HMA 3 & 9425 & НМА 0.3 & 9925 & HМА 1.3 & 10945 & HМА 2.3 & 9678 & HМА 3.3 & 8308 \\
\hline & HМА 4 & 9645 & & & & & & & & \\
\hline & $\begin{array}{l}\text { Avg. } \\
\text { HMA }\end{array}$ & 9763 & $\begin{array}{l}\text { Avg. } \\
\text { HMA }\end{array}$ & 9838 & $\begin{array}{l}\text { Avg. } \\
\text { HMA }\end{array}$ & 10605 & $\begin{array}{l}\text { Avg. } \\
\text { HMA }\end{array}$ & 9650 & $\begin{array}{l}\text { Avg. } \\
\text { HMA }\end{array}$ & 8280 \\
\hline
\end{tabular}

Table 7. ITSM test results at $20{ }^{\circ} \mathrm{C}$ from laboratory and trial field phase. 